MATEC Web of Conferences 40, 07003 (2016)

DOI: $10.1051 /$ matecconf/20164007003

(C) Owned by the authors, published by EDP Sciences, 2016

\title{
Economic Analysis in Restructured Electricity Supply Industry (ESI) for Malaysian Market Model
}

\author{
N. Mohamad ${ }^{1}$, P.D Abdul Aziz², and F.Z. Hamidon ${ }^{3}$ \\ ${ }^{1}$ Electrical Technology Section, Universiti Kuala Lumpur British Malaysian Institute, Malaysia \\ ${ }^{2}$ Electrical Technology Section, Universiti Kuala Lumpur British Malaysian Institute, Malaysia \\ ${ }^{3}$ Electrical Technology Section, Universiti Kuala Lumpur British Malaysian Institute, Malaysia
}

\begin{abstract}
Before 1980s, the generation, transmission and distribution vertically related sectors have typically been tied together within a utility. It has been either, investor owned and state-regulated or owned by the local municipality. Each sector was thought of as a natural monopoly. During that era, there were two main reasons accelerated for restructuring needs. The first one was to widen up the choices of electricity for customers. And the second one was due to rapid expansion capacity needs in generation, transmission and distribution. In Malaysia, the Malaysian Electricity Supply Industry (MESI) has aimed to restructure its current model to become a wholesale market model. In 1992, by introducing the Independent Power Producers (IPPs) in the loop, MESI applies Single Buyer model. Single Buyer model is one of the existing models available under the restructuring apart from Pool and Bilateral. This paper evaluates the economic benefits for Malaysia with the current structure from the side of electricity provider. A case study with load variation for three different maximum demands is considered in this paper. The mathematical equation developed by zero Loss of Load Probability is applied to evaluate the economic benefits.
\end{abstract}

\section{Introduction}

Electricity Supply Industry (ESI) has been undergoing rapid change reshaping an industry that has been under vertically integrated monopoly for many decades. The term restructuring and deregulation [1] are both used to describe the transformation process of electricity supply industry (ESI. Restructuring, which taking place mainly in early 1990s refers to changes in its structure. In the context of electricity market, there are four models usually used for market arrangements; namely, Single buyer, Pool trading, Bilateral Contract and Multilateral model. However, the selection of the trading models depends on the technical and economic justification which is determined by the regulatory [2].

\section{Malaysian Electricity Supply Industry (MESI)}

Malaysia was first supplied with electricity in $20^{\text {th }}$ century. Over the years and with revolution experienced, Tenaga Nasional Berhad (TNB) is the key body in supplying the electricity to consumers. TNB function is also included generation and transmission. In order to encourage the competition and reduce the monopoly, Malaysian government is then introduced the Independent Power Producer (IPP). These IPPs are to assist to avoid the possibility of electricity shortage that might occur due to increasing in demand. In 2010 for instance, total electricity demand in Peninsular Malaysia was increased by $7.8 \%$ from $94,748 \mathrm{GWh}$ in 2009 to $102,139 \mathrm{GWh}$ [3]. In fact, Energy Commission (EC) in its annual 2013's report tabulated the maximum electricity demand was keep on increasing from 2010 till 2013. Despite the existence of IPPs, Sabah that located in East Malaysia is still facing supply insufficiency due to low availability and reliability of some power producers.

Current structure for Malaysian market model is designed in such a way the IPPs may and can only sell the generator power to TNB Transmission (TNBT) and TNB Distribution (TNBD) as illustrated in Figure 1. And TNB is authorizes in deciding which IPP and its capacity based on the demand's projection.

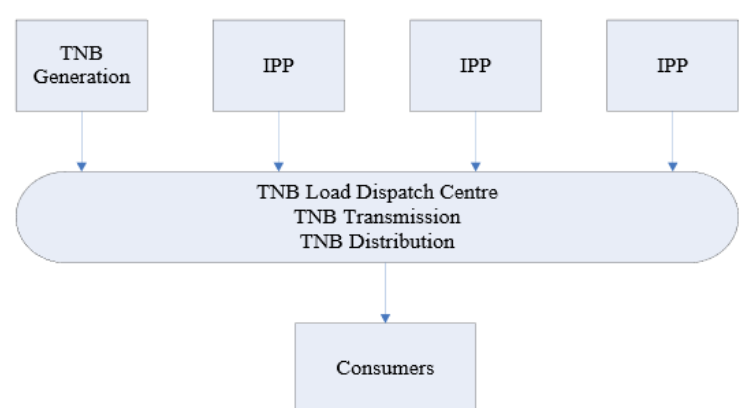

Figure 1: Current structure for Malaysian electricity supply industry 
A mechanism is also created where these IPPs will only generate the required electricity based on the agreement signed between the two parties. The Purchase Power Agreement (PPA) that signed for 15 to 20 years clearly clarifies the purchase and sale of contract capacity and energy. 2011 witnessed the maximum demand of the grid system was increased by $2.7 \%$ to $15,476 \mathrm{MW}$. However, no new capacity was added to the existing generation capacity. Having PPA, out of the total generation capacity, $7054 \mathrm{MW}$ came from TNB generations and only the remaining was from IPPs [4]. Figure 2 shows the registered IPPs with its licensed generation capacity.

\begin{tabular}{|c|l|c|}
\hline Bil & \multicolumn{1}{|c|}{ IPP } & $\begin{array}{c}\text { Licenced } \\
\text { Capacity (MW) }\end{array}$ \\
\hline 1 & $\begin{array}{l}\text { YTL Power Generation Sdn. } \\
\text { Bhd }\end{array}$ & 1170.00 \\
\hline 2 & $\begin{array}{l}\text { Genting Sanyen Power Sdn. } \\
\text { Bhd }\end{array}$ & 762.00 \\
\hline 3 & $\begin{array}{l}\text { Segari Energy Ventures Sdn. } \\
\text { Bhd }\end{array}$ & 1303.00 \\
\hline 4 & Powertek Bhd & 440.00 \\
\hline 5 & Port Dickson Power Bhd & 440.00 \\
\hline 6 & Musteq Hydro Sdn. Bhd & 20.00 \\
\hline 7 & TNB Janamanjung Sdn. Bhd & 2100.00 \\
\hline 8 & $\begin{array}{l}\text { Teknologi Tenaga Perlis } \\
\text { Consortium Sdn. Bhd }\end{array}$ & 650.00 \\
\hline 9 & Nur Generation Sdn. Bhd & 440.00 \\
\hline 10 & Pahlawan Power Sdn. Bhd & 334.00 \\
\hline 11 & Prai Power Sdn. Bhd & 350.00 \\
\hline 12 & GB3 Sdn. Bhd & 640.00 \\
\hline 13 & Panglima Power Sdn. Bhd & 720.00 \\
\hline 14 & Tanjung Bin Power Sdn. Bhd & 2100.00 \\
\hline 15 & $\begin{array}{l}\text { Kapar Energy Ventures Sdn. } \\
\text { Bhd }\end{array}$ & 2420.00 \\
\hline 16 & $\begin{array}{l}\text { Jimah Energy Ventures Sdn. } \\
\text { Bhd }\end{array}$ & 1400.00 \\
\hline
\end{tabular}

Figure 2: Independent Power Producers (IPP)

\section{Mathematical Equations for MESI}

From the previous chapter, the single buyer market model that applies in MESI is based on PPA where the purchasing agency is responsible to buy the power generated by the GENCO [5]. Common practice, the contracts between the purchasing agency and the GENCO had taken or pay PPAs with a fixed capacity charges for such that the purchasing agency would have payment obligations regardless of whether the power is actually needed or not. The agreement states the agreed capacity with purchase and selling price. Based on those conditions, the mathematical equation for generation incomes and demand charges for single buyer can be written as:

For total generation income under MESI, GTM, the formula is:

$$
G_{T M}=G_{T N B}+G_{S E S B}+G_{S E B}
$$

If each of GTNB, GSESB and GSEB is represented by GiM, then total generation for each generator can described as:

$$
G_{i M}=P_{G i M} \times C_{G i M}
$$

where $P_{G i M}=$ Maximum power capacity generated by $i$ th generator under MESI

$C_{G i M}=$ Price offered by $i$ th generator under MESI

$G_{T M}=$ Total generation income under MESI

$$
\text { Thus; } \quad G_{T M}=\sum_{i=1}^{k=3}\left(P_{G i M} \times C_{G i M}\right)
$$

Following figures; Figure 3 to Figure 5 describe the comparison of generation costs for their own generation and purchased energy for the last three years.

\begin{tabular}{|l|c|c|c|}
\hline Type of Energy & 2010 & 2011 & 2012 \\
\hline $\begin{array}{l}\text { Own Generation } \\
\text { (sen/kWh) }\end{array}$ & 16.16 & 18.22 & 20.28 \\
\hline $\begin{array}{l}\text { Purchased Energy } \\
\text { (sen/kWh) }\end{array}$ & 21.99 & 24.68 & 25.05 \\
\hline
\end{tabular}

Figure 3: Generation costs for TNB

\begin{tabular}{|l|c|c|c|}
\hline Type of Energy & 2010 & 2011 & 2012 \\
\hline $\begin{array}{l}\text { Own Generation } \\
\text { (sen/kWh) }\end{array}$ & 17.42 & 24.30 & 16.16 \\
\hline $\begin{array}{l}\text { Purchased Energy } \\
\text { (sen/kWh) }\end{array}$ & 22.33 & 25.80 & 17.90 \\
\hline
\end{tabular}

Figure 4: Generation costs for Sabah Electricity Sdn Bhd (SESB)

\begin{tabular}{|l|c|c|c|}
\hline Type of Energy & 2010 & 2011 & 2012 \\
\hline $\begin{array}{l}\text { Own Generation } \\
\text { (sen/kWh) }\end{array}$ & 14.6 & 21.8 & 25.89 \\
\hline $\begin{array}{l}\text { Purchased Energy } \\
\text { (sen/kWh) }\end{array}$ & 14.2 & 13.2 & 11.72 \\
\hline
\end{tabular}

Figure 5: Generation costs for Sarawak Electric Berhad (SEB)

\section{Economic Benefits}

Using the equations derived in section III, the economic potential for MESI is evaluated with a case study. A situation that being considered is load variations for three different maximum demands to depict different maximum demand that occur in different states. The selection of the generators for each area is based on the highest maximum capacity from generators listed in Figure 2. Each generator has a maximum generated capacity with specific price as indicated in Table 1 .

TABLE 1

GENERATOR'S MAXIMUM CAPACITY AND BID PRICE 


\begin{tabular}{|l|c|c|}
\hline \multicolumn{1}{|c|}{ Generator } & $\begin{array}{c}\text { Maximum } \\
\text { Capacity, MW }\end{array}$ & $\begin{array}{c}\text { Bid Price, } \\
\text { RM/MWh }\end{array}$ \\
\hline \multicolumn{3}{|c|}{ Peninsular Malaysia } \\
\hline TNB Generation & 4000 & 2.028 \\
\hline $\begin{array}{l}\text { Kapar Energy } \\
\text { Ventures }\end{array}$ & 2420 & 2.505 \\
\hline \multicolumn{3}{|c|}{ Sabah } \\
\hline SESB Generation & 4000 & 1.616 \\
\hline TNB Janamanjung & 2100 & 1.790 \\
\hline \multicolumn{3}{|c|}{ Sarawak } \\
\hline SEB Generation & 4000 & 2.589 \\
\hline $\begin{array}{l}\text { Tanjung Bin Power } \\
\text { Sdn. Bhd }\end{array}$ & 2100 & 1.172 \\
\hline
\end{tabular}

Three assumptions are applied in this condition:

i) No limited transfer capacity on transmission line (unconstrained dispatch)

ii) No losses on transmission elements

iii) Loss of Load Probability (LOLP) is equal to zero

Based on Table 2, the bidding prices for Peninsular Malaysia from respective generators are charted in Figure 6 to Figure 8.

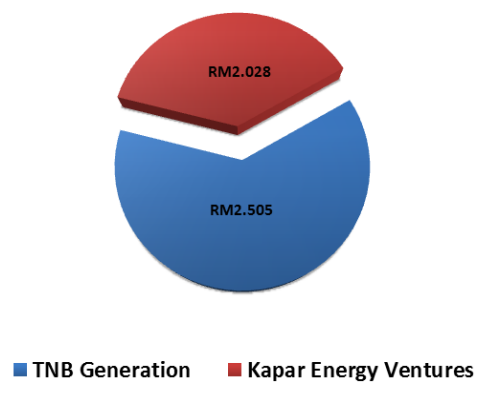

Figure 6: Pricing curve from submitted bids for Peninsular Malaysia

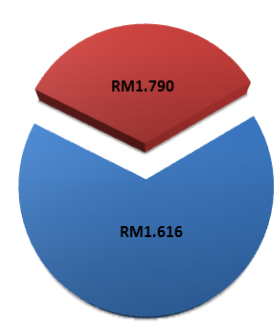

—SESB Generation $\quad$ TNB Janamanjung

Figure 7: Pricing curve from submitted bids for Sabah

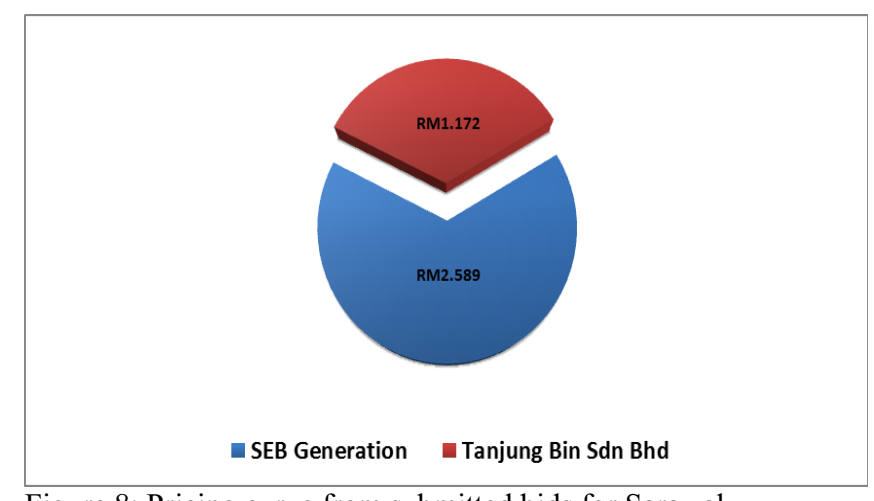

Figure 8: Pricing curve from submitted bids for Sarawak

\subsection{Results with Demand Variations}

A very simple case study is introduced to resemble the actual different maximum demand occurs in different states. Load variations of $2500 \mathrm{MW}$ and $5000 \mathrm{MW}$ are used respectively. The generation expenses for three generators are calculated based on mathematical Equation 1 till Equation 3 and tabulated in Table 2.

TABLE 2

GENERATION INCOMES FOR THREE GENERATORS AT DIFFERENT DEMAND

\begin{tabular}{|l|c|c|c|}
\hline \multirow{2}{*}{ Generator } & \multicolumn{3}{|c|}{ Load variations (MW) } \\
\cline { 2 - 4 } & $\mathbf{3 0 0 0 M W}$ & $\mathbf{4 5 0 0 M W}$ & $\mathbf{6 0 0 0 M W}$ \\
\hline \multirow{2}{*}{ TNBG } & RM 6,084 & RM9,365 & RM 13,122 \\
\hline SESBG & RM 4,848 & RM 7,359 & RM 10,044 \\
\hline \multirow{2}{*}{ SEBG } & RM 7,767 & RM 10,942 & RM 12,700 \\
\hline
\end{tabular}

The overall comparison for generation companies involved is shown in Fig 9. While detail comparisons for different generators at specific demand are summarized in Figure 10, 11 and 12. 


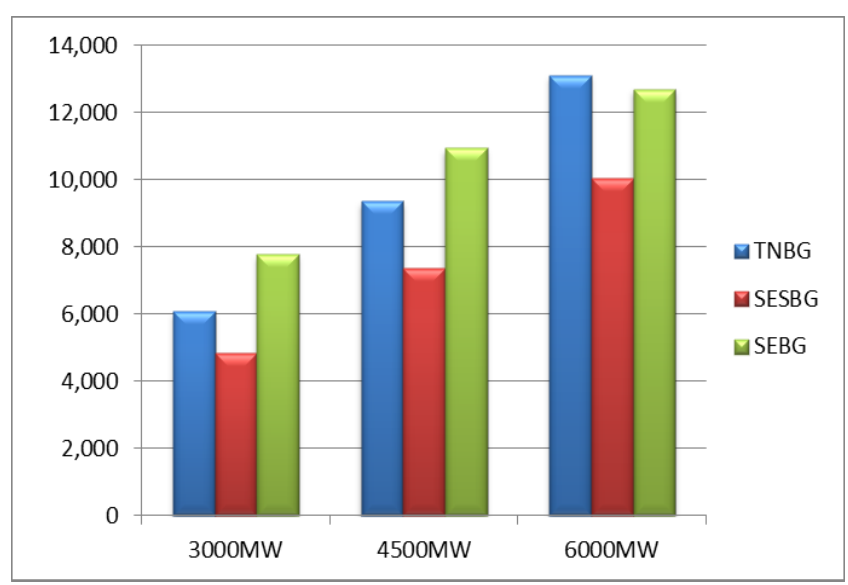

Figure 9: Overall generation incomes for three different maximum demands

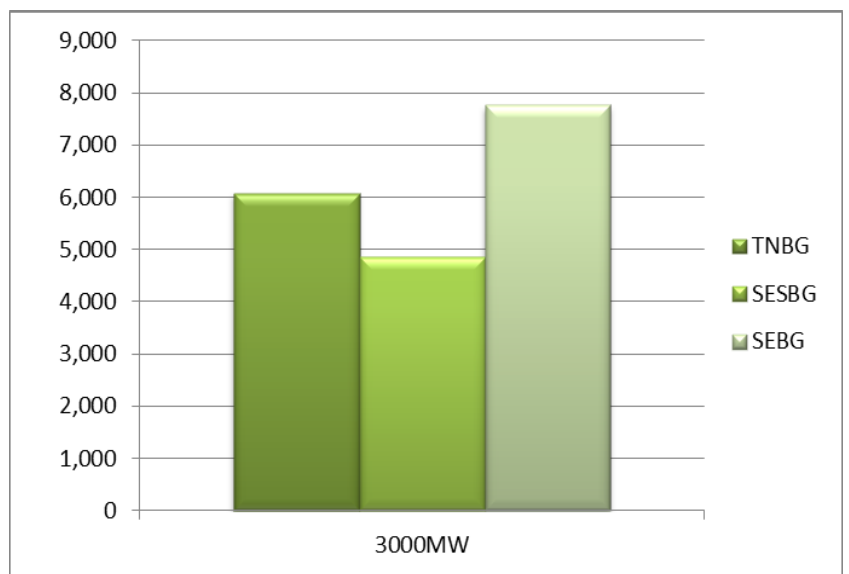

Figure 10: Generation incomes at maximum demand of 3000MW

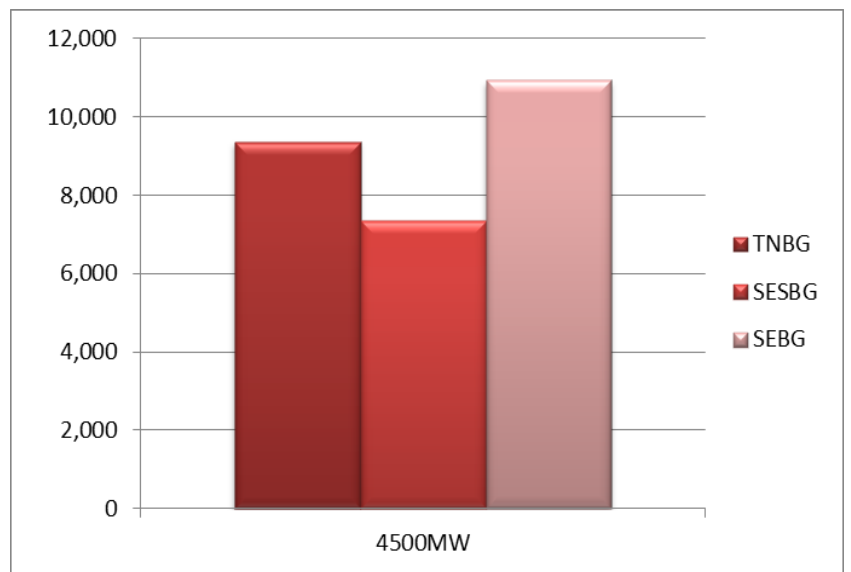

Figure 11: Generation incomes at maximum demand of $4500 \mathrm{MW}$

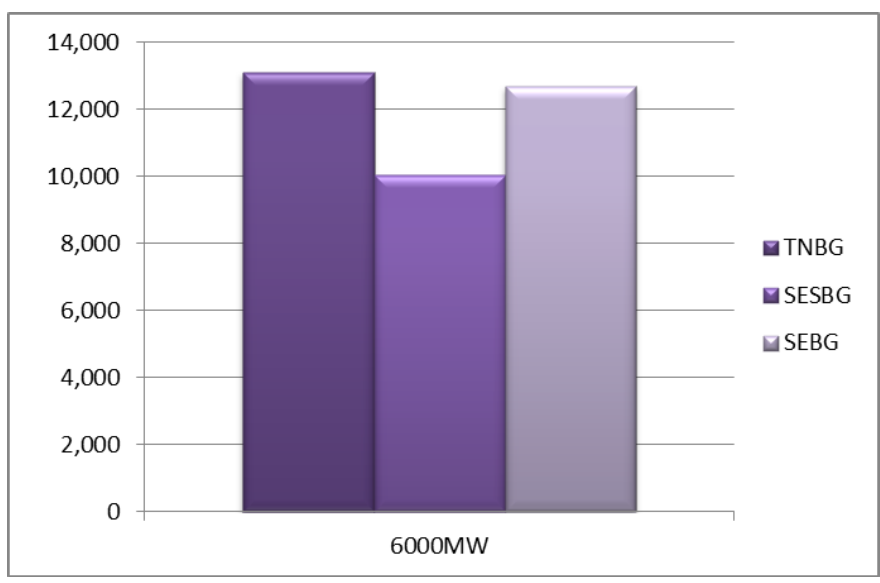

Figure 12: Generation incomes at maximum demand of 6000MW

From the comparison charts, it can be seen that the value is increasing as the maximum demands increase. From Fig 3 till 5, the generation costs for different areas are varies hence the incomes produced also varies. Obviously the highest income generated in Peninsular Malaysia followed by Sabah and Sarawak. This is mainly due to larger population in Peninsular compared to Sabah and Sarawak.

However, as Malaysia implements Single Buyer and there's PPA signed between the authorities (TNB, SESB or SEB generations) and IPP, certain amount still need to be paid to these power producers regardless the power is utilized or not. To further explain this, consider maximum demand for the year of 2012:

a) Actual maximum Demand for $15,476 \mathrm{MW}$ 2012

b) Maximum generated capacity $12,000 \mathrm{MW}$ from TNBG

c) Maximum capacity signed under $\quad 5,000 \mathrm{MW}$ PPA

d) Price paid for TNBG

RM2.028/MWh

e) Price paid to IPP

f) Electricity tariff

RM2.505/MWh

* commercial tariff is in used

Net profit for TNB for the year of 2012 is by taking the equation of $(a \times f)-\left[\left(\begin{array}{lll}b & x & d\end{array}\right)+\left(\begin{array}{lll}c & x & e\end{array}\right)\right]$ to yield net profit worth RM 29,685.80

Again, assumption that is being used in this scenario is the tariff applied is commercial tariff for low voltage. Where in the real case, those electricity are also meant for domestic, commercial and for industrial use. The more the domestic usage, the lesser the net profit will be as the tariff for that particular aspect is cheaper. Similar scenario can also be expected for Sabah and Sarawak with different maximum demand. As such, it can be seen the only party that borne the consequence is TNB.

It has been an issue for Malaysian electricity market as well due to this PPA and IPPs. In late 1990s, it was publicized that TNB suffered massive profit erosion as a 
result of pay-out to IPPs. Not to mention the hike of fuel cost that also needs to be borne by TNB. To balance the situation out, TNB is suggested to revise the PPA by shorten out the duration of agreement. TNB also has revised the electricity tariff twice in the period of 10 years.

\section{Conclusion}

From the above analysis, it can be observed that generation incomes are increasing as the maximum demand increases. In other words, generation income is proportioned with the maximum demand. Different state will have their own generation income style that based on maximum demand, population and also geographical aspect that lead to electricity price. For example, having the lowest generating capacity, SESBG became the lowest generator in income. It is considered as 'not healthy' as not all generated electricity will be utilized. Consequently, it is either the generator that needs to bear all the generating cost or it will be shared by end users that normally need to pay higher in electricity tariff. Under Single Buyer model, the TNB, or SESB or SEB as the middle party is the party that needs to consider both from the generation side and also demand charge. Having the case study as a simulation model and simple maximum demand scenario prove that Malaysia should also consider other than Single Buyer model should to maintain and ensure the equal importance of customers and generators.

\section{References}

1. D. Kirschen, G. Strbac, Fundamentals of Power System Economics, University of Machester Institute of Science \& Technology, John Wiley \& Sons, 2004

2. S. Borenstein, J. Bushnell, Electricity Restructuring:Deregulation or Reregulation, Energy Regulation, 23(2)

3. Electricity Supply Industry in Malaysia: Performance and Statistical Data Information 2010, Department of Energy Management and Industry Development, Energy Commision, 2012

4. Electricity Supply Industry in Malaysia: Performance and Statistical Data Information 2011, Department of Energy Management and Industry Development, Energy Commision, 2013

5. L. Lovei, The Single Buyer Model, The World Bank Group, Private Sector \& Infrastructure Network, December 2000

6. S. Stoft, Power System Economics-Designing Markets for Electricity, IEEE Press, Wiley Interscience, 2002

7. A. Sultana, Pool versus Bilateral Markets: A Global Overview, Operation of Restructured Power Systems, Department of Electrical Engineering, University of Waterloo, Canada, 2004

8. D. Newberry, The Rationale for a Market Monitoring Process, Southeast Europe Electricity
Market Monitoring Workshop, University of Cambridge, 2005

9. M. O'Mahony, M. Vacchi, The Electricity Supply Industry: A Study of an Industry in Transition, No: 177; 85, National Institute Economic Review 2001

10. D. Newberry, T. McDaniel, Auctions and Trading in Energy Markets: An Economic Analysis, Center for Energy and Environmental Policy Research, Massachusetts Institute of Technology, 2001 